\title{
Implicaçōes narratológicas em La Ciociara, de Alberto Moravia e Vittorio de Sica
}

\author{
Narratologic implications in La Ciociara, \\ from Alberto Moravia and Vittorio de Sica
}

Marinês Lima Cardoso

Universidade do Estado do Rio de Janeiro, Rio de Janeiro, RJ, Brasil

\begin{abstract}
Resumo: A literatura e o cinema possuem semelhanças e divergências, pois, apesar deste último ser uma expressão artística essencialmente visual, ele se aproxima da literatura no que diz respeito ao uso das palavras e à finalidade de contar histórias. Trata-se de uma arte que tem as suas próprias especificidades, como a imagem e o som, mas que apresenta, assim como a literatura, uma natureza narrativa. Neste trabalho, serão discutidas algumas estratégias narrativas, como o narrador, o espaço e o tempo, no romance La Ciociara (1957), de Alberto Moravia, e na sua adaptação cinematográfica, Two women (1960), de Vittorio De Sica.
\end{abstract}

Palavras-chave: Narratologia. Adaptação cinematográfica. Alberto Moravia. Vittorio De Sica.

Abstract: Literature and cinema have convergences and divergences, because, despite the latter being an essentially visual artistic manifestation, it gets close to literature regarding the use of words and the purpose of telling stories. It is about some kind of art that possesses its own particularities, such as the image and sound; on the other hand, it presents, such as literature does, a narrative nature. In this paper, some narrative strategies will be discussed, for instance, narrator, space and time in La Ciociara (1957), a novel by Alberto Moravia, and in its movie production Two Women (1960), by Vittorio de Sica.

Key words: Narratology. Movie production. Alberto Moravia. Vittorio De Sica

\section{Introdução}

A adaptação de uma obra literária para o meio cinematográfico sempre suscitou um grande debate entre críticos da literatura e do cinema. Nessa transformação, por se tratar de dois sistemas de significação diferentes, as mudanças são necessárias, visto que cada uma dessas artes possui características próprias. Tanto o cinema quanto a literatura 
Marinês Lima Cardoso

apresentam, em geral, uma história narrada por uma instância narrativa estabelecida em algum lugar, em um determinado tempo, envolvendo um certo número de personagens. Verifica-se, assim, que parece não existirem dúvidas em relação ao diálogo constante entre a literatura e o cinema e nem sobre o caráter de arte narrativa que o cinema apresenta. Como afirma Antonio Costa: “... o cinema é uma linguagem com suas regras e suas convenções. É uma linguagem que tem parentesco com a literatura, possuindo em comum o uso da palavra das personagens e a finalidade de contar história" (1989, p. 27).

Não se pode esquecer que a prática narrativa se configura como elemento fundamental, pois está sempre presente praticamente em todas as atividades humanas e, no caso do cinema, isso não seria diferente, pois essa arte é por natureza narrativa. Tal atividade se revela de várias formas e gêneros no mundo, estabelecendo uma dinâmica constante de reprodução de elementos factuais ou fictícios. Barthes apresenta a narrativa como um fenômeno presente em todos os tempos, lugares e em todas as sociedades e elenca as formas de sua manifestação:

\footnotetext{
... a narrativa pode ser sustentada pela linguagem articulada, oral ou escrita, pela imagem fixa ou móvel, pelo gesto ou pela mistura ordenada de todas essas substâncias; está presente no mito, na lenda, na fábula, no conto, na novela, na epopéia, na história, na tragédia, no drama, na comédia, na pantomima, na pintura, no vitral, no cinema, nas histórias em quadrinhos, na conversação (1971, p.19).
}

Verifica-se, assim, que para Barthes, a prática de narrar constitui uma atividade exercida por grupos humanos de todas as classes e culturas, adquirindo, assim, um estatuto de "universalidade". Angelo Moscariello (1981, p.66) também destaca o caráter narrativo do filme, em que as noções de narratividade são fundamentais para um estudo mais profundo, ou seja, embora sejam representações autônomas e independentes, o destino narrativo é também comum ao cinema, fato que o libera da ideia de uma arte somente visiva.

Porém, um dos elementos que diferencia uma obra literária de uma cinematográfica diz respeito à comunicação verbal e visual, pois enquanto o cinema permite ao espectador a percepção imediata da cena representada, o romance possibilita ao leitor a sua própria 
imagem mental dos acontecimentos narrados. Segundo Aumont et al (2013, p.135), o cinema aparece como um dos modos mais realistas entre todas as artes devido a sua capacidade de reproduzir o movimento e, ao mesmo tempo, restituir o ambiente sonoro em que se passa a ação. Ou seja, essa impressão de realidade experimentada pelo espectador é sobretudo devido à riqueza perceptiva, simultânea, da imagem e do som. Entretanto, o parentesco entre a literatura e o cinema, ou melhor, a convergência dessas duas artes quanto aos propósitos narrativos no que se refere à manifestação da linguagem, não pode fazer esquecer que o cinema, bem como a literatura, possui especificidades para o desenvolvimento de sua narrativa. o cinema possui a imagem em movimento que já indica uma perpétua transformação de um estado de coisa representada para um outro estado. Além dis-

Implicações narratológicas em La Ciociara so, diferentemente do romance, cujo enunciado é formado apenas da língua, o cinema compreende imagens, palavras, menções escritas, ruídos e músicas, tornando, assim, a organização da narrativa fílmica mais complexa.

\section{Romance e filme}

Neste trabalho, buscar-se-á tratar alguns aspectos relacionados à adaptação cinematográfica de uma obra literária, a saber o romance La ciociara (1957), de Alberto Moravia e o filme Two women (1960), do diretor Vittorio De Sica, no que diz respeito a algumas categorias narrativas, como o narrador, o espaço e o tempo.

O romance em estudo é resultado da experiência vivida pelo próprio escritor romano durante os anos do regime fascista, em que fora obrigado a abandonar Roma e se refugiar em uma região montanhosa junto com outras pessoas na mesma situação. Moravia soube através de um amigo que estava na lista das pessoas procuradas pelo regime ditatorial de Mussolini e que seria preso. É interessante observar, para compreender melhor a posição de Moravia neste contexto, que o regime ditatorial daqueles anos suspeitava da sua atividade literária, uma vez que, através de seus romances e contos, ele fazia uma forte crítica a este regime. $\mathrm{O}$ escritor romano foi um dos escritores que mais agiu na cultura italiana do século XX através das denúncias feitas nas suas obras literárias. Desde a publicação do seu primeiro romance, Gli indifferenti (1929), ele retratou alguns problemas que assolavam o homem, como a incomunicabilidade e a falta de valores morais. As suas obras 
desnudavam uma nova situação social e histórica que se delineava na Itália durante a segunda Guerra Mundial e nos anos opressivos do regime fascista.

Moravia permaneceu durante nove meses em um vilarejo da Ciociaria, uma região montanhosa denominada Sant'Agata, que no romance terá o nome de Sant'Eufemia, e retornou a sua cidade após a chegada dos soldados americanos que a liberaram do domínio alemão. Em Roma, baseando-se nas recordações das dificuldades vividas naquele período, ele escreveu as primeiras cinquenta páginas de um romance com um Marinês narrador-protagonista feminino, porém o abandonou e deu continuidaLima Cardoso de a outros trabalhos. Mas, em 1954, o romance foi retomado e três anos depois, publicado com o título La ciociara, que indica a região geográfica da protagonista. Esse espaço de tempo entre as primeiras páginas e a redação final do romance é explicado pelo próprio Moravia:

\footnotetext{
Scrissi le prime cinquanta pagine della "Ciociara" nel 1946, prima ancora della "Romana". Poi smisi perché non sapevo come continuare. Mi resi conto che l'estrema vicinanza dell'esperienza vissuta era un impaccio che impediva il sereno ripensamento dei fatti e delle figure. Ora è diverso: sono passati dieci anni e quella cronaca violenta e brutale può essere collocata su un piano più distaccato e obiettivo (MORAVIA, 2005, p.xx).
}

Como se pode observar, era necessária uma distância dos acontecimentos vividos por ele para narrar os fatos e as ações dos personagens. Somente após dez anos, Moravia retoma aquelas páginas com um distanciamento da matéria narrativa.

O romance apresenta a história de Cesira, uma camponesa que se mudou para Roma após o casamento e foi obrigada a tomar conta do pequeno negócio de alimentos do marido e cuidar da educação da filha após ficar viúva. Com a ocupação nazista, mãe e filha saem de Roma para se refugiar em uma pequena cidade, mas o trem que as conduzia não pode prosseguir o seu destino devido aos bombardeios que atingiram a estrada férrea. Desse modo, as duas mulheres se refugiam em um pequeno vilarejo de Sant'Eufemia, com a esperança de retornar tão logo a cidade fosse liberada. Nesse lugar, Cesira entra em contato com outros refugiados e conhece Michele, um jovem intelectual que imprimirá profundas mudanças no seu comportamento. Com a chegada dos aliados, 
todos regressam para suas cidades, inclusive Cesira e Rosetta. Durante a viagem, as duas mulheres se refugiam em uma igreja abandonada e são violentadas por um grupo de soldados marroquinos diante da imagem da Virgem Maria. Todas as privações passadas nas montanhas bem como essa violência física alterarão a visão sobre a guerra e sobre a existência humana que as duas mulheres tinham até o momento.

Vale ressaltar que Moravia sempre desenvolveu atividades relacionadas à sétima arte; ele elaborou roteiros para o cinema e escreveu muitas críticas sobre filmes e ensaios sobre o cinema para alguns jornais. Além disso, participou diretamente no processo de filmagem de alguns filmes, inclusive naqueles adaptados da sua produção literária, como Il disprezzo, em 1963, com o diretor Jean-Luc Godard e Gli indifferenti, em 1964, com Francesco Maselli.

Implicações narratológicas em La Ciociara

O próprio Moravia considerava o cinema uma forma de arte autônoma com uma linguagem própria e uma dinâmica característica e, muitas vezes, mais eficaz na representação da realidade. Conforme revela Maria Grazia Di Mario, para o escritor romano, tudo isso deriva do fato de tratar-se de uma escritura por imagens, que tem um alcance mais veloz e atinge todo um coletivo:

Nell'economia del film la parola è in opposizione subalterna rispetto all'immagine (...) ciò deriva dal fato che l'immagine ha un suo linguaggio, un suo stile, mentre ancora non esiste uno stile del parlato. Ed è giusto che sia così. Il regista dispone infatti di un mezzo visivo: perché dovrebbe far rivaleggiare il dialogo con l'immagine (2013, p. 90).

Ainda segundo a autora, a atitude de Moravia era de respeito diante dos pontos de vista técnicos dos diretores com os quais trabalhou. O escritor, para Moravia, tem a obrigação de calar-se diante das exigências expressivas do diretor, baseadas sobre as necessárias escolhas técnicas.

\section{Reflexões sobre o narrador, o espaço e o tempo}

Todo texto narrativo, seja literário seja audiovisual, apresenta algumas estruturas de base comum e é através do confronto entre essas estruturas e aquelas do texto de partida literário que a adaptação pode ser estudada. Segundo Coutinho, o cinema tem várias influências da literatura, 
... de logo manifestando-se a da continuidade da novela ou do romance tradicionais, o que descobre a arraigada dependência do filme em relação ao enredo, à história, que de direito pertence à literatura; tal herança viu-se facilitada pelo tipo de apresentação de dois gêneros artísticos: ambos se processam no tempo, segundo a índole sucessiva das recepções" (1996, p.104).

$\mathrm{Na}$ obra literária, existe um narrador que relata os fatos ao leitor,

Marinês Lima Cardoso enquanto no filme, as imagens, em uma quantidade infinita, adquirem uma instância narrativa. No cinema, é a câmera que exerce a função narrativa, pois focaliza, recorta e aproxima as imagens para o espectador. Convém destacar que essa câmera que tudo registra não é neutra, existe alguém que seleciona e combina as imagens que serão apresentadas ao público.

No romance em destaque, as ações são narradas pela protagonista, ou seja, temos um narrador que nos apresenta o universo ficcional a partir do ponto de vista da personagem principal. A voz narrativa do romance é aquela de uma camponesa simplória que se torna comerciante, dotada de profunda perspicácia e iniciativa, tanto em relação aos outros comerciantes quanto a seus pretendentes. É Cesira, por exemplo, que descreve a saída da sua cidade para se casar com Vincenzo e os primeiros anos felizes do seu matrimônio: "Ah, i bei tempi di quando andai sposa e lasciai il mio paese per venire a Roma" (MORAVIA, 2005, p. 05). Esse narrador-protagonista não tem acesso ao estado mental das demais personagens, pois ele está limitado aos seus pensamentos e percepções.

Ao discorrer sobre a instância narrativa cinematográfica, Gaudreault e Jost (2009, p.64) tratam das noções de narrador explicito e implícito. 0 narrador explícito, neste caso, corresponde aos personagens, na medida em que o cinema mostra personagens em ação que imitam os humanos em suas diversas atividades cotidianas, entre elas, a de falar. Desse modo, as personagens ao falarem, estão também narrando. Já o segundo tipo corresponde ao "grande imagista" ou ao mega-narrador, aquele que manipula e organiza as diversas matérias de expressão fílmica. É por isso que para Aumont et al (2013, p.111), na narrativa cinematográfica, o narrador seria “... o diretor, na medida em que ele escolhe determinado tipo de encadeamento narrativo, determinado tipo de decupagem, determinado tipo de montagem, por oposição a outras possibilidades oferecidas pela linguagem cinematográfica". Dessa ma- 
neira, o narrador é aquele que produz, simultaneamente, uma narrativa e uma história.

No romance em estudo, o primeiro capítulo assume a função de introdução, pois apresenta as qualidades físicas e sociais da protagonista: ela evoca a sua infância e a sua nova vida em Roma. Mais tarde, é introduzido o nascimento da filha Rosetta, que representa para ela a pureza de caráter e bondade. Neste aspecto, é importante observar que a descrição do caráter da filha é marcada por observações da narradora que preanunciam o que estaria para acontecer: “... e anche adesso che lei, come ho detto, è cambiata dal bianco al nero..." e ainda: “... non sapevo che a Roma mi aspettava la disgrazia" (MORAVIA, 2005, p.28). Desse modo, o leitor sabe que acontecerá uma mudança do caráter da jovem, mas não conhece a sua causa, embora seja induzido a acreditar Implicações narratológicas em La Ciociara que seja devido à experiência da guerra. Todos esses fatos são revelados por Cesira que adota uma posição de narradora das suas memórias, com o seu olhar em direção ao passado. Não podemos esquecer que o narrador é sempre um papel fictício, agindo como se a história fosse anterior a sua narrativa. Ele transforma em narrativa uma experiência vivida, selecionando e dando sentido às suas sensações e percepções. Mas, ao mesmo tempo, podem ocorrer manipulações, ainda que involuntárias, dos diálogos realizados entre ele e as outras personagens, uma vez que a distância temporal pode não permitir a reprodução exata das palavras pronunciadas.

Já no filme, a história, uma vez que não faz uso da linguagem escrita, não apresenta esse tipo de narrador protagonista que informa ao leitor os acontecimentos e as suas lembranças. Na obra em estudo, o espectador acompanha as ações do filme, que seguem o fio das ações de Cesira. Desse modo, quem assiste ao filme não conhece a história precedente da protagonista, como a sua partida do seu vilarejo para Roma, pois a história começa com a cidade sendo bombardeada e mãe e filha se trancando dentro da mercearia, o marido é apenas citado e o comércio de Cesira ocupa um breve momento no início.

Observa-se, assim, que De Sica escolhe um caminho diferente para retratar a história da vida dessas duas mulheres. $O$ caráter da protagonista é revelado à medida que o filme se desenrola e, do mesmo modo, as cenas adquirem uma focalização a partir do olhar de Cesira. Através dessa focalização, vimos a conhecer que a protagonista é uma mulher que possui a determinação de uma comerciante ávida por seu 
trabalho, pois é o comércio que move os seus instintos mais básicos e a impulsiona em seus ideais de prosperidade financeira. Além da devoção ao seu trabalho, observa-se também uma grande devoção à sua filha; Cesira conserva toda a sua esperança em sua filha, seu verdadeiro e talvez único ponto vulnerável.

Na obra de De Sica, quando as duas mulheres partem de Roma há a câmera que as acompanha pelas estradas e pelas regiões pelas quais elas passam. $O$ espectador toma contato com os caminhos tortuosos das duas protagonistas ao mesmo tempo que elas, pois é conduzido pelo

Marinês Lima Cardoso percurso das mulheres através do movimento da câmera.

É através desse deslocamento e da permanência das personagens nas montanhas que se assistirá à transformação pela qual passará Cesira, de mulher simples e inculta a uma pessoa com uma consciência moral mais aprofundada. Esses dois elementos narrativos, o espaço e o tempo, são percebidos de modo diferente nas obras narrativa e fílmica. Pellegrini et al afirmam que todas as formas narrativas, sejam as literárias sejam as visuais:

\footnotetext{
... estão direta ou indiretamente articuladas em sequências temporais, não importa se lineares, se truncadas, invertidas ou interpoladas. A diferença entre a literatura e o cinema, nesse caso, é que, na primeira, as sequências se fazem com palavras e, no segundo, com imagens (2003, p.18).
}

Enquanto na literatura, a questão do tempo pode ser descrita com precisão ao longo da leitura, como por exemplo quando se indica, em poucas palavras, que se passaram dias, meses ou anos, no cinema, essa percepção não é tão precisa, embora a sensação do tempo fluindo se verifique através das imagens em movimento. O leitor sabe que Cesira e Rosetta permaneceram nove meses afastadas de Roma, protegendo-se da guerra enquanto o espectador não tem uma ideia precisa desse tempo, sabe somente que as duas mulheres passaram alguns meses protegidas da guerra. Na narrativa fílmica, a percepção da passagem temporal se verifica através do espaço que muda, como por exemplo, quando se mostra a noite ou o dia, o que revela, assim, que o tempo no filme é, em geral, relativo a um espaço. Isso porque, no filme, tempo e espaço são inseparáveis, pois as relações temporais adquirem um aspecto quase espacial do mesmo modo que o espaço adquire características temporais. 
O espaço e o tempo constituem elementos importantes na articulação e no desenvolvimento do material narrativo tanto no cinema quanto na literatura. Enquanto o aspecto temporal, no filme, está relacionado ao espaço, a representação deste último é mais perceptível do que no romance, uma vez que na obra literária são necessárias muitas palavras para indicar uma imagem que no filme é percebida em um instante. No cinema, a espacialização do elemento temporal produz profundas alterações nas formas de perceber o espaço e de representá-lo. A esse propósito, Hauser afirma que: "O espaço perde a qualidade estática, a passividade serena, e torna-se agora dinâmico; adquire existência diante de nossos olhos, por assim dizer. É fluido, ilimitado, inacabado, um elemento com história própria, com seu próprio esquema e processo de desenvolvimento" (2003, p.971). É por isso que Pellegrini et al utiImplicações narratológicas em La Ciociara lizam os termos invisível e visível para se referirem, respectivamente, ao tempo e ao espaço: “... o tempo, que é invisível, é preenchido com o espaço ocupado por uma sequência de imagens visíveis; misturam-se, assim, o visível e o invisível" (2003, p.18).

O espaço do cinema é literal, pois os objetos e as suas dimensões são análogas aqueles do mundo real, enquanto no romance, observa-se um caráter abstrato que exige, assim, uma reconstrução mental do leitor. Além do espaço vislumbrado pela câmera, existe outro não mostrado, que também se revela importante na medida em que o leitor é chamado a reelaborar o que está fora da tela. A imagem limita o campo espacial da visão, pois submete o espectador somente ao que é oferecido pela câmera, proporcionando, assim, uma visão objetiva por parte do espectador. Já a literatura permite ao leitor a reelaboração do material narrado, revelando, desse modo, o seu caráter subjetivo. Entretanto, como afirma Brito (1995, p.192), o espaço mostrado na tela não constitui todo o espaço ficcional de um filme, mas apenas uma parte deste. Desse modo, a ausência da imagem apresenta também uma significação na construção da narrativa. $O$ crítico revela:

\footnotetext{
O que a teoria da linguagem tem revelado e sistematizado é que o espaço efetivamente mostrado na tela faz parte de um espaço ficcional maior, que o espectador é conduzido a imaginar. Além de todo o vazio em torno do retângulo da tela (acima, à direita e à esquerda), concebe-se um espaço, lá adiante, escondido atrás do cenário mais próximo, ou da paisagem mais longínqua e, em sen-
} 
Assim, apesar da imagem limitar o campo espacial da visão, pois ela apresenta ao espectador o que é apreendido pela câmera, no espaço não mostrado ocorre uma interpretação efetiva a partir da observação do espectador, pois este é capaz de preencher as lacunas não reveladas pela câmera.

Gaudreault e Jost, no estudo sobre a narrativa cinematográfica,

Marinês Lima Cardoso

E, já que o fotograma vem antes da sucessão de fotogramas, a temporalidade no cinema deve efetivamente se apoiar sobre o espaço para chegar a se inscrever no centro da narrativa. 0 tempo não começa a existir a não ser quando se opera a passagem entre um primeiro fotograma (que já é espaço) e um segundo (que também já é espaço) (105:2009).

Enquanto isso, o narrador da narrativa escritural deve fazer uma espécie de discriminação, uma vez que ele não pode descrever, ao mesmo tempo, o quadro espacial e a ação no qual esta se passa. Desse modo, ele deve escolher o que narrar, ocorrendo, muitas vezes, a ausência de algumas informações espaciais consideradas "decorativas" e não úteis à narrativa. Devido a sua capacidade de exprimir tudo, a língua não poderá nunca representar todas as relações de ordem espacial e, por isso, uma narrativa escritural não conseguirá retratar simultaneamente os parâmetros espaciais e temporais com os quais ela se relaciona. Em La ciociara, o narrador descreve o trajeto que mãe e filha fazem para escapar dos perigos da guerra, revelando detalhadamente as recordações de Cesira do lugar no seu tempo de menina:

Questi scalini erano le coltivazioni a terrazza che noialtri ciociari chiamiamo macere, le quali poi consistono in tante strisce lunghe e strette di terreno fertile, sorrette ciascuna da un mucchio di pietre a secco. (...) Io le macere le conoscevo bene; da ragazza avevo lavorato come una bestia a portare sul capo canestri di pietre per tirar su i muriccioli di sostegno e poi mi 
ero abituata ad andare su e giù per i sentierucoli ripidi e le scalinatelle che fanno comunicare l'una macera con l'altra (MORAVIA, 2005. p.64).

Já na narrativa fílmica, o espaço está sempre presente, pois as informações relativas ao aspecto espacial são fornecidas em abundância pela câmera. No cinema, há a apresentação simultânea de vários elementos informacionais e não somente uma determinada informação espacial. Quando Cesira faz esse percurso, são visualizados pelo espectador todos os detalhes que a câmera consegue enquadrar e não apenas um determinado ponto, como poderia acontecer no romance. Observa-se, desse modo, que para o cinema é muito difícil dar o enfoque apenas na ação e não no quadro espacial no qual esta se desenrola. Além Implicações narratológicas em La Ciociara disso, no filme, o espaço adquire uma importância vital ao permitir a explicação geográfica da origem da personagem, pois, à medida que a protagonista faz a viagem em direção às montanhas romanas, o espectador visualiza os aspectos geográficos do vilarejo em que ela nascera. Percebe-se, assim, que a construção desse espaço se verifica através do deslocamento das duas mulheres, pois a partir de Roma, leitor e espectador tomam contato com esse construto narrativo.

Como já acenado anteriormente, a questão espacial, no romance e no filme, permite-nos também acompanhar a conversão moral pela qual passará a protagonista. Cesira, tentando preservar sua filha e buscando suprir a escassez de alimentos, precisa encontrar um lugar protegido para ambas e, por isso, as duas mulheres abandonam Roma. Nesse momento, a protagonista não tinha consciência do mal que a guerra acarreta à humanidade e nem mesmo sabia distinguir a diferença entre aliados e nazistas. Ela pouco se importava com quem venceria a guerra, queria apenas que o conflito terminasse e pudesse retornar para Roma para cuidar do seu pequeno negócio e de sua filha. Durante o trajeto, ela nutre a esperança de uma possível tranquilidade longe dos bombardeios de Roma, porém, essa viagem demonstra não ser tão simples assim quanto ela planejava, pois, a topografia não é a mesma do seu tempo de menina.

É somente após conhecer Michele, em Sant'Eufemia, que se assiste a uma mudança de visão de mundo da personagem, verificando-se o encontro da protagonista com um pensamento até então ignorado, uma consciência maior pelos males que a guerra inflige ao ser humano. 
A protagonista começará a perceber a importância da solidariedade e do temor da fome.

É importante destacar que a permanência nas montanhas bem como o contato com Michele é muito mais evidente no texto do que no filme. A esse respeito, Betton destaca que é comum, no universo fílmico, que o tempo não seja respeitado, ocorrendo, assim, elipses ou concentrações temporais:

Marinês

Lima Cardoso

248
O plano de corte, que permite interromper a ação sem qualquer problema para retomá-la posteriormente, é largamente utilizado para contrair o tempo, para reforçar a intensidade das ideias, evitando assim o supérfluo, e também para dar a entender algo sem que seja necessário exprimi-lo diretamente. (1987, p.25)

No texto moraviano, durante esse longo período, são dedicadas muitas descrições e pormenores da vida cotidiana dos refugiados que tentavam sobreviver afastados do local da guerra, preocupando-se com os seus instintos básicos. Os diálogos entre Cesira e Michele são mais constantes, possibilitando ao leitor acompanhar gradualmente o processo de educação moral pelo qual passa a protagonista. Já no filme, são apresentados poucos questionamentos moral e político de Michele, restringindo-se a algumas falas os ensinamentos do jovem intelectual a Cesira. O primeiro contato de Cesira com Michele se verifica na chegada das duas mulheres às montanhas, onde os refugiados estavam reunidos diante de uma mesa farta. 0 momento de satisfação de todos é quebrado pelo discurso aborrecido de Michele que questiona o próprio pai em relação ao dinheiro e ao seu posicionamento diante da guerra. Para o jovem, é absurdo o pai dar tanta importância a sua riqueza enquanto existem tantas pessoas sofrendo diante dos males da guerra. Tanto no filme quanto no romance, Cesira apenas observa esse desentendimento entre pai e filho e tenta interagir com os demais.

É oportuno, nesse momento, deter-nos no trajeto empreendido por mãe e filha, que, no filme, revela-se aparentemente mais "curto" do que no romance. Na adaptação, o deslocamento das duas mulheres se mostra mais dinâmico e fluido por se tratar de imagens em movimento. $O$ aspecto espacial que a câmera revela não apresenta um caráter estático e abstrato como acontece na narrativa verbal em que o leitor deve reconstruir em sua mente o espaço onde se desenvolve a ação. 
Já no romance, como revelado anteriormente, o leitor toma conhecimento dos detalhes geográficos das estradas pelas quais passam as duas mulheres através do discurso da protagonista. Quando chegam ao seu destino, o perigo lhes parecia distante, entretanto não desapareceu totalmente, pois ali também Cesira deveria mostrar-se eficaz na sua sistematização nas montanhas e na obtenção de proventos. Ela buscava ali um refúgio temporário até que pudesse voltar à tranquilidade de Roma com Rosetta e retomar seu pequeno negócio. Entretanto, a permanência de mãe e filha nas montanhas e o contato com Michele imprimirá fortes alterações nesse plano estabelecido. As preocupações individuais almejadas por ela serão abaladas em Sant'Eufemia, ou seja, todas as expectativas criadas por ela no trajeto Roma-Sant'Eufemia sofrerão uma ruptura, pois a Cesira que retorna para Roma já é uma mulher educada Implicações narratológicas em La Ciociara moralmente.

Ainda em Roma, durante os preparativos para a partida, a protagonista revela que sentia que a viagem duraria mais do que o esperado: “... ma nello stesso tempo avevo non so che pressentimento non soltanto di un'assenza più lunga ma anche di qualche cosa di triste che mi aspetasse nell'avvenire" (MORAVIA, 2005, p.19). Essa informação não é compartilhada pelo espectador, pois o filme dá pouco enfoque aos momentos que antecedem a partida das duas.

No romance, o leitor tem a percepção de que os fatos narrados por Cesira já foram experimentados por ela, enquanto o filme apresenta a história das duas mulheres como sendo vivenciada no presente. A esse propósito Brito afirma: “diferentemente do que se dá na literatura, todo o tempo do cinema tende a ser sentido como presente, ao que se atribui normalmente a força da imagem" (1995, p.187). Além disso, a permanência das duas mulheres nas montanhas é bastante sinalizada através da descrição da passagem do dia para a noite bem como das estações do ano que mudam, como a chegada do inverno em que Cesira deve providenciar roupas apropriadas para a estação. São descritas as cenas dos dias chuvosos em que os personagens observam a lentidão do tempo que, para eles, parecia não passar. Verifica-se, desse modo, que, na narrativa, o aspecto temporal pode ser medido através de um sistema de palavras que permite a percepção de um tempo que avança. $\mathrm{Na}$ obra cinematográfica, esse período se revela de modo mais abreviado, isso porque, conforme esclarece Betton, “o domínio da escala do tempo é um dos procedimentos mais notáveis do cinema: na tela, a duração de 
Marinês Lima Cardoso um fenômeno pode ser, à vontade, interrompida, alongada, encurtada e até mesmo invertida" (1987, p.17).

O cinema, por sua vez, criou alguns sinalizadores para que se possa estabelecer a passagem do tempo, como medições feitas pelos próprios personagens e a claridade ou penumbra que indicam o dia ou a noite. No filme em destaque, os momentos de claridade são observados quando os personagens se reúnem para as refeições ou nos períodos em que Cesira, Rosetta e Michele passeiam e conversam ao ar livre. A penumbra é verificada no interior das cabanas no momento em que os personagens se recolhem para dormir.

Durante a permanência nas montanhas, Cesira se empenhava em preservar a filha do mal e se sentia segura em relação ao aspecto financeiro, pois dispunha de bastante dinheiro. As passagens do romance que destacam o caráter ávido da protagonista pelo dinheiro, fazendo o "comércio negro" de alimentos, não são indicadas no filme. De Sica suprime essa parte do romance em favor de um maior dinamismo no filme, pois, após a cena inicial do bombardeio, quase em seguida passa-se à viagem de mãe e filha em direção à Sant'Eufemia. No romance, o leitor vem a saber que a protagonista fazia todos os sacrifícios e até mesmo se arriscava para buscar alimentos a fim de atender aos seus clientes. Em tempos de guerra, todos que podiam, estocavam gêneros alimentícios e pagavam, por isso, somas bem altas em troca do alimento tão desejado. Cesira vendeu todo o seu estoque e parecia não se dar conta de que assim não haveria nada para ela e nem para sua filha consumirem.

Em Sant'Eufemia, a protagonista se vê obrigada a gastar muito para obter provisões para ela e a filha, comprando dos camponeses locais gêneros alimentícios necessários. Estes, durante a guerra, lutavam para conservar o pouco que tinham ou para melhorar a própria condição econômica, aproveitando-se da falta de alimentos e vendendo-os a altos preços. É nesse momento que se começa a delinear uma nova reflexão por parte da protagonista que, devido às dificuldades impostas pela guerra, percebe que a ânsia por dinheiro não é nada diante da fome e da necessidade básica de um alimento.

Finalmente, com a chegada dos aliados, os refugiados deixam Sant'Eufemia e Cesira e Rosetta empreendem uma nova viagem em direção à Roma. Mas, o retorno de mãe e filha não se apresenta tão imediato e fácil como imaginara a protagonista e sim, lento e cansativo. Se durante a viagem de ida às montanhas, Cesira se mostrava esperançosa 
com dias melhores na sua terra natal, longe da guerra, agora, no retorno, após as privações causadas pela guerra e a violação de sua filha, ela não tem perspectivas de um futuro melhor. No romance, enquanto são conduzidas em um carro dos oficiais aliados, Cesira observa a paisagem, tentando reconhecer algum aspecto tranquilo e seguro de suas lembranças dos anos vividos nesse local, porém o percurso se revela diferente:

\footnotetext{
Le montagne adesso non stavano tanto a ridosso della strada; ci scendevano dolcemente; e non erano più tanto verdi, erano sassose e pelate. Tutto il paesaggio diventava adesso ad ogni passo sempre più nudo, più deserto e più severo. Era il paesaggio dove ero cresciuta bambina e lo ricosnocevo sempre più, così che il senso un po' scuorante e quase pauroso della sua selvatichezza e solitudine veniva in parte mitigato da quello di rientrare in un luogo che mi era familiare (MORAVIA, 2005, p.259).
}

É interessante observar que a descrição geográfica do vilarejo feita pelo personagem-narrador no momento que antecede a violência se revela sombria e preanuncia o que estava para acontecer. De Sica apresenta uma solução diferente nesse trecho do romance, pois enquanto as duas mulheres fazem esse percurso a pé, a câmera apresenta ao espectador a aridez do lugar. Ela observa a pouca vegetação, o pequeno rio, as casas fechadas e a ausência de pessoas e animais, revelando uma total falta de vida no lugarejo.

\section{Considerações finais}

Os meses passados nas montanhas correspondem à parte central do romance, que, segundo o próprio escritor romano, parecia uma passagem longa e monótona: "Avevo temuto che la parte centrale tra l'inizio e la conclusione fosse un po' monotona perché non vi succede niente" (2005, p.XXV). Mas, ainda segundo o autor, esses capítulos deveriam dar um aspecto de espera, como a dos aliados que eram frequentemente citados pelos outros personagens. Esses capítulos centrais estabelecem um contraste entre o longo período da guerra, quase sem problemas, e a catástrofe final, quando o pior parecia já ter ocorrido. Essa lentidão revela uma preparação para a alteração de comportamento que será mais evidente em Rosetta, após o encontro com os soldados marroquinos. O tempo estendido nessa parte do romance e do filme sugere um 
Marinês Lima Cardoso

clima de perigo, pois, através de uma monótona esperança, tudo levava a crer que após essa longa pausa das duas mulheres nas montanhas, algo de mais grave ainda poderia acontecer. A violência sofrida por mãe e filha não ocorre durante os meses de refúgio, mas quando o perigo parecia ter sido superado. Tudo acontece no interior de uma igreja, sob o altar da Virgem Maria, na região em que sua mãe nascera, em que Rosetta é violentada não pelos fascistas, mas justamente pelos soldados que vinham liberar a Itália das mãos dos fascistas. É destacada, assim, a repentina transformação da jovem, descrita pela mãe como perfeita, que depois da violência sofrida, torna-se apática e indiferente a tudo, inclusive à própria mãe. A partir desse momento uma atmosfera de estranheza invade a personalidade de Rosetta, modificando a sua visão sobre os homens. Ela parece aceitar o sexo que lhe haviam forçado como uma forma de revolta, cedendo e buscando outros homens para desespero de sua mãe. A explicação para esse comportamento é dada pela própria Cesira:

... lei in quel momento che era stata violenta dai marocchini, aveva avuto la volontà spezzata e, al tempo stesso, qualche cosa, che lei aveva sinora ignorato, le era entrato nella carne, come in fuoco, e la bruciava e le faceva desiderare di essere di nuovo trattata a quel modo che l'avevano trattato i marocchini, da tutti gli uomini nei quali si imbatteva (MORAVIA, 2005, p. 297).

Vale ressaltar que o estupro de Rosetta representa a violência que a guerra causa a toda a população, revelando uma dor individual e coletiva que atinge o ser humano. E é por isso que o próprio autor afirmou que o título mais adequado do romance seria 0 estupro: "Il titolo resterà $L a$ ciociara benché il titolo più appropriato sarebbe Lo stupro. Anzi addirittura, alla maniera classica: Lo stupro d'Italia" (2005, p. XVII). Moravia revela ainda que, na época da publicação, escreveu a Bompiani, proprietário da editora, que La ciociara não era um romance sobre o amor, mas um romance sobre os horrores que a guerra causa a todos.

Romance e filme apresentam um final diferente, porém ambos mostram a reconciliação entre mãe e filha. No filme, após uma breve discussão, Cesira revela à filha que Michele fora assassinado pelos soldados alemães e é, nesse momento, que Rosetta esboça uma emoção. A reação da menina faz com que sua mãe sinta um pouco de esperança em 
reencontrar a bondade na filha, que havia sido perdida depois da violência sofrida. Nesse momento, com a lembrança de Michele, os antigos sentimentos de mãe e filha retornam e elas se abraçam. Ocorreu, nesse caso, uma subtração a partir do momento que se optou por excluir do filme uma parte da obra literária. Subtrair uma parte de um texto literário na adaptação significa evidenciar um tipo de leitura sobre o texto, considerando, assim, alguns elementos mais significativos do que outros. Observa-se que De Sica optou por um final mais sentimental na sua leitura da obra moraviana, que pode ser ilustrado através das palavras de Betton: "Com coisas, e não com palavras, numa linguagem que cabe a nós decifrar, o cineasta oferece-nos uma visão pessoal, insólita e mágica do mundo" (1987, p. 01).

O romance de Moravia vai além desse momento, pois após a notíImplicações narratológicas em La Ciociara cia da morte do jovem e a reaproximação de mãe e filha, os personagens se deslocam em direção a Roma no caminhão do amante de Rosetta. No caminho, os três são surpreendidos por um grupo que mata o jovem e as duas se veem sozinhas mais uma vez na estrada. Entretanto, a ambição material de Cesira se revela ainda nesse momento, pois antes de seguir o caminho, ela pega o dinheiro de Rosario. A protagonista sente um grande remorso pelo "roubo" diante do cadáver e toma consciência da realidade em que se encontra e da insensatez do ser humano, principalmente diante do olhar da filha: "Allora, non so come, mi ricordai del denaro che Rosario aveva nascosto nel cruscotto, stesi la mano, presi l'involto e me lo caccio in seno. Rosetta mi vide fare il gesto e mi lanciò uno sguardo che mi parve quasi di riprovazione" (MORAVIA, 2005, p.309). Essa troca de olhares entre elas direciona os dois personagens à percepção dos atos que a guerra ocasiona, pois Cesira recrimina a filha pela nova conduta com os homens, enquanto a filha lhe desaprova a sua atitude diante do "furto" a um cadáver. Além disso, Moravia, nesse momento final da obra, retoma os ensinamentos de Michele quando Cesira se lembra que, conforme ele falara, todos estavam "mortos vivos". Agora, a protagonista compreende melhor o que ele dissera e percebe que sempre fora uma "morta viva", pois não enxergava as desgraças que assolavam a grande maioria das pessoas, preocupando-se somente com os seus próprios interesses.

La ciociara termina com mãe e filha regressando para Roma, cientes de que a experiência pela qual passaram marcaria profundamente suas vidas. Rosetta acha que perdeu tudo e descobre o valor do aspec- 
to carnal, pois além da violência física, a jovem fora violentada na sua pureza e no seu credo religioso. Ela vê desmoronar, assim, a sacralidade da sua fé sobre a qual havia construído a própria personalidade porque é violentada em uma igreja, refúgio hipoteticamente seguro. 0 processo de transformação da protagonista fica evidente nas duas leituras, pois a Cesira que retorna não é mais aquela mulher inculta que só pensava no bem-estar seu e de sua filha, ela adquire uma nova visão do ser humano e da vida. Responsável por essa mudança é Michele, que exerce o papel de educador da protagonista, refletindo sobre a situação em que a guerra os

Marinês Lima Cardoso reduzira. O jovem sempre fora incompreendido pelos demais refugiados e inutilmente tentou mostrar a eles o que a guerra significava, mas cada grupo tinha interesses próprios e não conseguia compreendê-lo.

Pode-se perceber através da análise das obras de Moravia e de De Sica que a articulação dos elementos da narratologia, como o narrador, o espaço e o tempo, tanto na literatura quanto no cinema, é multifacetada, pois os processos de organização são dinâmicos e podem variar de acordo com a proposta de cada criador. Observou-se, também, que a adaptação cinematográfica é um processo que, partindo de um texto ficcional, apresenta a sua reescritura que nunca será igual ao texto base, pois ambos os textos são representações autônomas e independentes.

\section{REFERÊNCIAS BIBLIOGRÁFICAS}

AUMONT, Jacques et al. A estética do filme. Campinas: Papirus, 1995.

BARTHES, Rolando. Introdução à analise estrutural da narrativa. Petrópolis: Editora Vozes, 1971.

BETTON, Gérard. Estética do cinema. São Paulo: Martins Fontes, 1987.

BRITO, João Batista de. Imagens Amadas. São Paulo: Ateliê Editorial, 1995.

COSTA, Antonio. Compreender o cinema. Rio de Janeiro: O Globo, 1987.

COUTINHO, Evaldo. A imagem autônoma. São Paulo: Ed. Perspectiva, 1996. 
GAUDREAULT, Andre. JOST, François. A narrativa cinematográfica. Brasília: Editora Universidade de Brasília, 2009.

HAUSER, Arnold. História social da arte e da literatura. São Paulo: Martins Fontes, 2003.

MARIO, Maria Grazia di. La Roma di Moravia tra narrativa e cinema. Roma: Aracne Editrici, 2013.

MORAVIA, Alberto. La ciociara. Milano: Bompiani, 2005.

Implicações narratológicas em La Ciociara

MOSCARIELLO, Angelo. Cinema e/o letteratura. Bologna: Pitagora Editrice, 1981.

PELLEGRINI, T. et al. Literatura, cinema e televisão. São Paulo: Editora Senac São Paulo, 2003.

\section{REFERÊNCIA FILMOGRÁFICA}

Two women. Direção: Vittorio De Sica. Produção: Carlo Ponti. Roteiro: Vittorio De Sica, Cesare Zavattini. Versátil, 1960. 140 min, preto e branco.

Recebido em 17 de abril de 2016 Aceito em 22 de setembro de 2016 
